\title{
Intensive Diabetestherapie schützt vor Arteriosklerose
}

Fragestellung: Können schwere Hypoglykämien bei Diabetikern langfristig eine Koronarsklerose verstärken?

Hintergrund: In den großen Langzeitstudien zur antidiabetischen Therapie (ACCORD, ADVANCE, VADT) steigt die Zahl kardiovaskulärer Komplikationen bei Patienten mit schwerer Hypoglykämie. Das widerspricht der Ausgangshypothese derartiger Studien, nach denen eine zuverlässige Stoffwechselkontrolle die Arteriosklerose in allen Gefäßgebieten langfristig verhindern oder doch zumindest verzögern kann. Die Autoren haben deshalb untersucht, wie Hypoglykämien die Progression der Koronarsklerose beeinflussen.

Patienten und Methoden: Als schwer galten Hypoglykämien, die zu Bewusstlosigkeit oder akuten ärztlichen Maßnahmen führten sowie dokumentierte Glukosewerte unter $50 \mathrm{mg} / \mathrm{dl}$. In einer Subgruppe des VADT hatten 97 Patienten eine oder mehrere Hypoglykämien. Sie traten erwartungsgemäß häufiger bei intensiv (74\%) als bei konventionell (21\%) behandelten Patienten auf. Mittels Computertomografie wurde der koronare Kalziumscore zu Studienbeginn und nach 4,6 Jahren bestimmt.

\section{Originalie}

Saremi A, Bahn G D, Reaven P $D$ et al. A Link Between Hypoglycemia and Progression of Atherosclerosis in the Veterans Affairs Diabetes Trial (VADT). Diabetes Care 2016;39:448-54.
Ergebnisse: Am Studienende war bei Diabetikern mit Standardtherapie der Kalziumscore von 5,4 auf $11,15 \mathrm{~mm}^{3}$ $(\mathrm{p}=0,02)$ gestiegen, mit Intensivtherapie aber - trotz häufigerer Hypoglykämien - konstant geblieben. Wichtig sind zwei weitere Ergebnisse:
- Unter Standardtherapie nahm der Kalziumscore mit der Zahl der Hypoglykämien signifikant zu.

- Der Anstieg des Kalziumscores durch Hypoglykämien war abhängig von der Intensität der antidiabetischen Therapie, d.h. signifikanter Anstieg bei mittleren $\mathrm{HbA}_{1 c}$-Werten über 7,5\% und Konstanz bei Werten unter 7,5\%.

Schlussfolgerung: Obwohl es unter Intensivtherapie häufiger zu schweren Hypoglykämien kommt, sind diese nur in der Standardgruppe mit einem Anstieg des koronaren Kalziumscores korreliert.

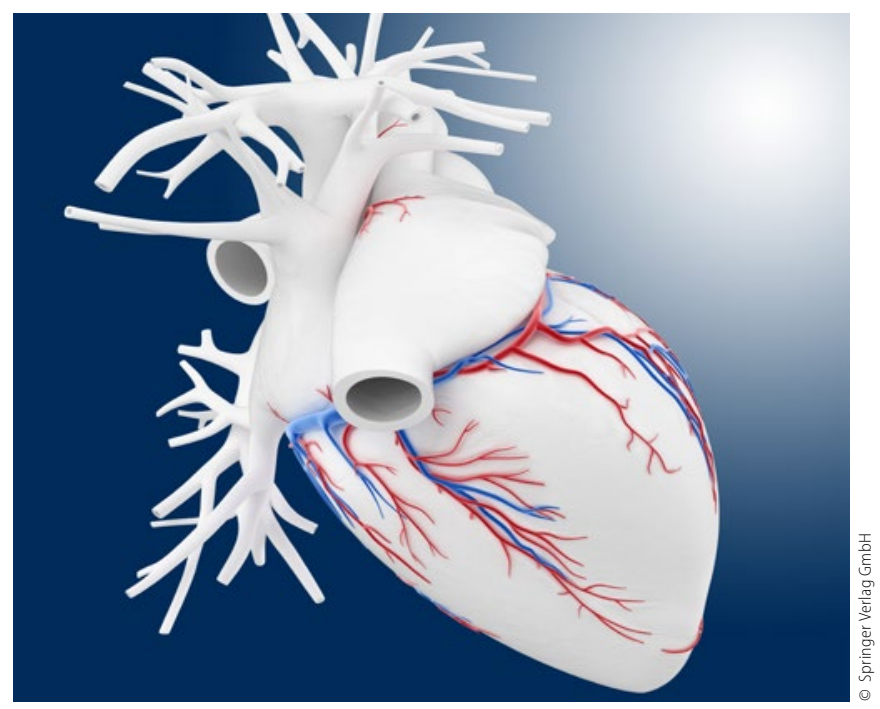

Hypoglykämien verursachen akut kardiovaskuläre Komplikationen, langfristig schützt die strenge BZ-Einstellung aber vor Koronarsklerose.

\section{- Kommentar von Prof. Dr. med. Heinrich Holzgreve}

\section{Akute und langfristige Folgen von Hypoglykämien sind verschieden}

Hypoglykämien verursachen sympathoadrenale Abwehrreaktionen, die zu akuten kardiovaskulären Komplikationen wie Herzinfarkte und Schlaganfälle führen können. Diese Nebenwirkungen der Therapie werden als Endpunkte erfasst und beeinträchtigen den Nutzen der Behandlung, besonders in der Gruppe der intensiv behandelten Diabetiker mit häufigeren Hypoglykämien. Ein ganz anderes Bild zeigt sich langfristig bei der Koronarsklerose.

Diese ist unter intensiver Therapie und niedrigerem $\mathrm{HbA}_{1 \mathrm{c}}$ nach 4,6 Jahren trotz häufigeren Hypoglykämien unverändert, während sie unter Standardtherapie deutlich und sogar mit der Zahl der Hypoglykämien ansteigt. Langfristig schützt also eine intensive antidiabetische Therapie - in Überein- stimmung mit der Ausgangshypothese der Langzeitstudien - vor Arteriosklerose.

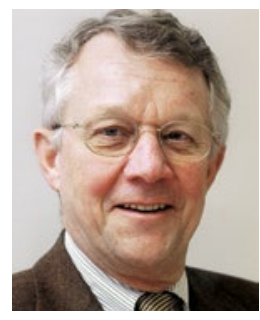

Prof. Dr. med. Heinrich Holzgreve

Internist, Kardiologische Praxis Burgstr. 7, 80331 München heinrich.holzgreve@t-online.de 